\title{
Do Voluntary Biotechnology Labels MATter TO THE CONSUMER? EVIDENCE FROM THE FLUID MiLK MARKeT
}

\author{
Kristin Kiesel, David Buschena, ANd Vincent Smith
}

\begin{abstract}
This article examines the effects on the demand of voluntary labeling for the use of genetically modified growth hormone for retail fluid milk using supermarket scanner data. Retail fluid milk tracks one of the first biotechnology products approved, is fairly standardized and ubiquitous, and allows for cross-sectional differentiation between labeled and unlabeled products and between conventional and organic brands. The results indicate that voluntary labeling increases the demand for recombinant bovine growth hormone free milk. In addition, the estimated effects of labeling appear to have increased over time.
\end{abstract}

Key words: biotechnology, random utility, scanner data, search, voluntary labeling.

Innovations through biotechnology enable agricultural producers to reduce production costs and/or enhance product quality for many livestock and crop commodities. At the same time, however, these innovations may affect the demand for the products that utilize those commodities. Many individuals, for example, are concerned about potential risks to human health although by no means all consumers have such concerns (Burton, Metcalfe, and Smith; Heiman, Just, and Zilberman). The use of the recombinant bovine growth hormone $(\mathrm{rBGH})$ in milk production has been a particular concern for some consumers as approximately one-third of the United States' dairy herd, about 3 million dairy cows, currently receive rBGH supplements (Monsanto).

Product labeling, particularly with respect to the provision of health and environmental information, is increasingly being used to provide information about product characteristics such as biotechnology content that

\footnotetext{
Kristen Kiesel is Ph.D. graduate student, Department of Agriculture and Resource Economics, University of California, Berkeley. David Buschena is associate professor, and Vincent Smith is professor, Montana State University, Bozeman, MT. This research was partially funded through a cooperative agreement between the Montana Agricultural Experiment Station and USDA-ERS.

The authors wish to thank Elise Golan of USDA-ERS for her valuable input. The authors also wish to thank Ian Sheldon and two anonymous reviewers for their helpful comments. We have benefited from seminar participants at Montana State University, the University of California at Berkeley, and the 2002 International Consortium on Agricultural Biotechnology Research held at Ravello, Italy. The authors also thank Dr. Wendy Stock for econometric advice. All errors remain our responsibility.
}

cannot otherwise be observed (Teisl and Roe). There is no clear international policy consensus about whether biotechnology labeling should be mandatory or voluntary. The United States supports voluntary labeling while the European Union supports mandatory labeling and just recently tightened their mandatory labeling regulations (Der Spiegel). In this context, quantitative evidence about the effects of labeling on the consumption of biotechnology food products provides policy relevant information about the economic value of labeling to agricultural producers, food processors, and consumers.

Previous studies of the effects of labeling have presented theoretical analyses of the possible effects of voluntary labeling on consumer demand, in some cases in the context of household production models (Smallwood and Blaylock; Caswell and Padberg; Teisl and Roe; Golan, Kuchler, and Mitchell). Teisl and Roe have emphasized the role of cognitive abilities, information, and time in defining the specific process by which labeling information is translated into consideration of product attributes. Teisl, Roe, and Hicks have adjusted Stigler and Becker's model of advertising to incorporate labeling effects on consumer knowledge about product attributes on the demand for a product. The theoretical model of the effects of labeling presented in the next section of this paper is innovative in that it sets a representative consumer's information search decision within a random utility specification of a 
household production model that reflects the uncertain nature of product information both in the absence and presence of labeling. The model provides clear predictions about the impact of increased labeling on the demands for a product that has a desirable, but costly to observe, characteristic.

This study investigates the predictions of this model by examining econometrically the effects of voluntary labeling about the use of biotechnology on aggregate fluid milk consumption in major U.S. markets. The U.S. fluid milk market provides an appealing case study for examining the effects of biotechnology labeling for several reasons. First, rBGH has been used in U.S. milk production since 1994, providing one of the earliest examples of the use of biotechnology in food production. ${ }^{1}$ Thus, it is possible to incorporate some longitudinal data into the analysis of consumption behavior, a facet that is especially important since market adjustments to labeling initiatives appear to occur slowly over time (Teisl, Roe, and Hicks). Second, fluid milk is a relatively standardized and ubiquitous processed commodity. Third, and perhaps most importantly, U.S. fluid milk consumption patterns involve product differences with respect to $\mathrm{rBGH}$-free unlabeled, labeled, and organic products, and conventional fluid milk products that typically include milk from dairy cows receiving rBGH supplements. National-level supermarket scanner data for the period 1995-99 compiled by Information Research, Inc. (IRI) provide quantitative information on these consumption patterns. These data, made available to the authors through a cooperative agreement with the USDA Economic Research Service, are combined with new information on product brands compiled by the authors to create a data set that can be used to estimate the effects of voluntary labeling on U.S. milk consumption patterns.

Previous empirical studies of the effects of food product labeling have tended to focus on the provision of nutrition information. Ippolito and Mathios found that nutritional labeling had significant effects on consumer choices. However, Mojduszka and Caswell, in a test of Grossmann's model of voluntary quality sig-

\footnotetext{
${ }^{1}$ The FDA approved rBGH for general use in November 1993 , but, in response to consumer concern, Congress placed a moratorium on its use until February 1994 (Aldrich and Blisard). The FDA requires that if milk producers choose to label their milk as rGBH free then the label must include a disclaimer citing the lack of scientific evidence for differences between milk produced with and without $\mathrm{rGBH}$.
}

naling, suggested that voluntary labeling information provided by firms is incomplete and not necessarily reliable. Teisl, Bockstael, and Levy used supermarket purchase data to assess changes in consumer behavior due to increased nutritional labeling. They reported that consumer's purchase behavior was significantly altered, but that purchases of "healthy" goods increased only in some, not all, food product categories.

Empirical studies of the effects of labeling on milk demand are mainly limited to the analysis of survey responses (McGuirk, Preston, and Jones; Grobe and Douthitt; Misra and Kyle). Aldrich and Blisard utilized monthly pooled time-series and regional (cross-section) data for the period 1978-96 to examine whether the introduction of $\mathrm{rBGH}$ milk reduced aggregate fluid milk consumption, but found no evidence of such an effect. The econometric results using scanner data presented in this article indicate that voluntary labeling affects consumption in important ways and that these effects do not diminish over time.

Retail supermarket scanner data used for this study present an otherwise effectively absent set of information for the purposes of demand estimation of specific fluid milk products on a wide geographic scale. These retail scanner data provide price and quantity data from actual purchases, rather than from relatively expensive hypothetical survey or experimental data. Additional secondary information can be obtained that permits identification of the products' labeling specifications. These data do offer some modeling challenges, including $(a)$ aggregation across consumers, precluding the use of income or other demographic variables; (b) the effective preclusion of specific data on desired firm decisions such as advertising expenditures on the product, shelf footage and placement, and production cost information; and $(c)$ some products are offered nationally, while others are offered only regionally. Although these considerations impose caveats in the interpretation of the results presented below, the use of retail scanner data allows estimation and testing of the effects of voluntary rBGH-free labels on consumer demand.

\section{Theoretical Model}

The model presented in this section incorporates the key elements of product attribute models (Becker; Rosen) with those of 
advertising and search models (Stigler; Stigler and Becker; Teisl and Roe; Teisl, Roe, and Hicks) within a random utility framework (McFadden; Thompson and Kidwell; Mathios) to account for the effects of labeling on consumer choice over milk products. We assume that consumers receive utility from milk produced without $\mathrm{rBGH}$ through subjective evaluation of health risks, environmental impacts, and consideration of their ethical beliefs. Additional product label information regarding these attributes facilitates more accurate assessments by consumers of product attributes related to these concerns.

The level of search over product attributes is integrated as a choice variable in a random utility framework. The randomness in utility arises from uncertainty about product attributes. This uncertainty can be reduced by search. Here, as in many information search models, an increase in the market share of products with the desired attributes, labeling information about these attributes, and previously acquired human capital each reduce the variance of the random component.

To focus on the choice between different fluid milk products, the constrained utility maximization problem is defined using a random utility function where $E[\cdot]$ denotes the expectation operator over a random term $r$ :

$$
\max _{\mathbf{x}, \mathbf{m}, t} E[U(\mathbf{x}, \mathbf{m}, r)]
$$

subject to

$$
Y=\sum_{i=1}^{n} p_{i} x_{i}+\sum_{j=1}^{k} p_{j} m_{j}+w t .
$$

The vector $\mathbf{x}$ includes all consumption goods except fluid milk products and the vector $p$ represents market prices of these commodities. Consumption from among the $k$-specific brands of fluid milk is denoted by $m$, where milk brand $j$ is purchased at price $p_{j}$. The household selects search time $(t)$ over milk products and their prices, where the opportunity cost of search time is $w$ per unit (hour). For reasons of expositional clarity and convenience, the household is assumed to search only on two attributes, the absence of $\mathrm{rBGH}$, and product price.

To further simplify the exposition, consider an environment in which only two branded milk products, $m_{1}$ and $m_{2}$, are available. Product $m_{1}$ denotes the rBGH-free milk product that may or may not be labeled. Product $m_{2}$ denotes an unlabeled "conventional" product that may contain milk from cows treated with rBGH. Suppose, for modeling purposes, that each consumer purchases either brand $m_{1}$ or brand $m_{2}$, but not both. The absence of $\mathrm{rBGH}$ in $m_{1}$ and the use of rBGH in $m_{2}$ are not known to the consumer with certainty in the absence of labeling or if labeling is voluntary, so the consumer's choice between $m_{1}$ and $m_{2}$ is modeled through random components $r^{1}$ and $r^{2}$, drawn from a distribution $R\left(\mu, \sigma^{2}(L, H, T)\right)$. The variance of the random component is assumed to be inversely related to labeling information $(L)$, previously acquired human or consumption capital $(H)$ that reflects the consumer's information set, and search time $(t)$.

The representative household's potential benefits from search over the properties of $m_{1}$ and $m_{2}$ are stochastic. This stochastic error structure arises because consumers are unsure about the rBGH status of the milk products and they are ex ante uncertain about the utility differences between consuming $m_{1}$ and $m_{2}$, defined through:

$$
E\left[U\left(\mathbf{x}, m_{1}, r^{1}\right)-U\left(\mathbf{x}, m_{2}, r^{2}\right)\right]=\delta .
$$

Equation (2) defines the expected difference in utilities for a given household between consuming $m_{1}$ and $m_{2}$, holding constant the choice over the vector of consumption goods. This expected utility difference is assumed to vary across consumers because of differences in consumer information, the amount of search undertaken, and differences in perceptions of health risks, in environmental concerns, and in ethical beliefs. For purposes of prediction, $\delta$ is assumed to be positive. Note that as $\delta$ approaches zero, the consumer approaches a state of indifference between $m_{1}$ and $m_{2}$.

Given that second-order derivatives are satisfied for the constrained maximization problem, optimal values for the choice variables $\mathbf{x}, m$, and $t$ can be found and the following equation can be derived using the dual of equation (2):

$$
\begin{aligned}
& U\left(\mathbf{x}^{*}, m_{1}^{*}, r^{1}\right)-U\left(\mathbf{x}^{*}, m_{2}^{*}, r^{2}\right) \\
& \quad=V^{*}(Y, w, \mu, L, H) .
\end{aligned}
$$

In equation (3), $V^{*}$ denotes the expected stochastic indirect utility difference function. Given equation (3), the probability that milk product $m_{1}$ will be selected over $m_{2}$ is

$$
P\left(V^{*}>0\right) \equiv P\left(m_{1}>0\right) .
$$




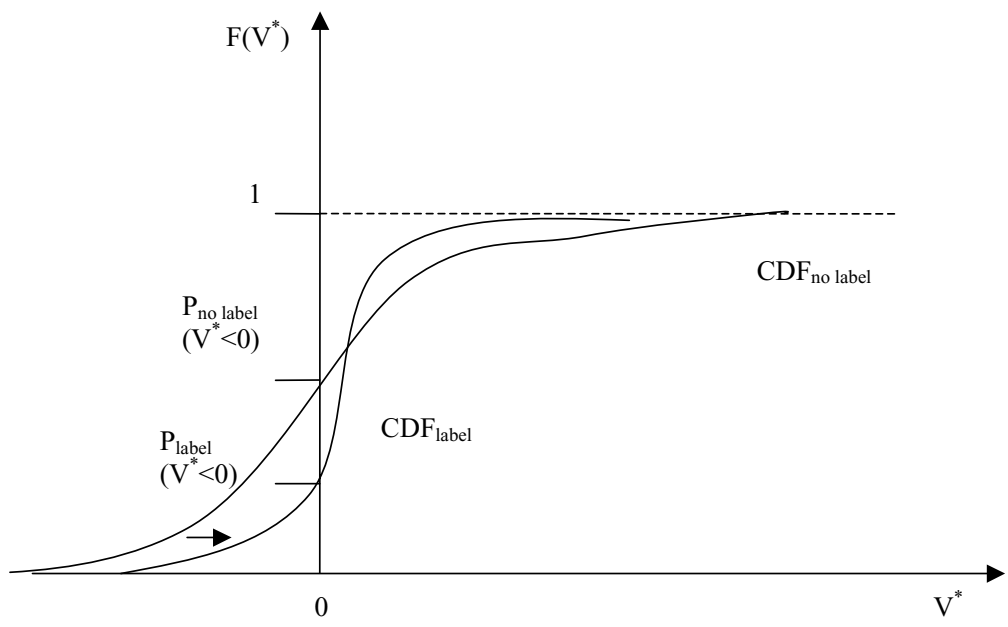

Figure 1. Cumulative density functions for $V^{*}$

The following prediction can be derived from this framework by differentiating equation (4) with respect to labeling of product $m_{1}(L)$, where labeling is defined as a continuous variable: ${ }^{2}$

$$
\frac{\partial P\left(m_{1}>0\right)}{\partial L} \equiv \frac{\partial P\left(V^{*}>0\right)}{\partial V^{*}} \times \frac{\partial V^{*}}{\partial L}>0 .
$$

In this context, labeling is modeled as a continuous variable to emphasize the possibility of an increase in the quality of labeling information. Both terms on the right-hand-side of equation (5) can be signed for households that have a positive $\delta$. The probability that $V^{*}$ is greater than zero increases with the mean of $V^{*}$. Ceteris paribus, for consumers with $\delta>$ 0 an increase in the amount of labeling information about the use of rBGH increases $V^{*}$ through a reduction in the variance of $r^{1}$. This mean preserving reduction in spread in the cumulative density functions for $V^{*}$ is illustrated in figure 1 for a qualitatively large change in labeling. The cumulative density function for $V^{*}$ in the absence of product labeling is denoted by $\mathrm{CDF}_{\text {no label }}$, and $\mathrm{CDF}_{\text {label }}$ represents the cumulative density function when milk is labeled as rBGH-free.

In practice and to the extent that it is measurable, labeling information is often discrete. For example, rBGH-free milk may be unlabeled (L1), or it may be voluntarily labeled as $\mathrm{rBGH}$-free (L2). Another labeling regime entails certification by an independent agency,

\footnotetext{
${ }^{2}$ Income effects from labeling are assumed to be zero in this derivation, although provision of labeling information may decrease search time for some households.
}

as is the case for all labeled organic milk products (L3), which must be rBGH-free to be certified organic (although additional factors such as concerns about pesticide residue or support for organic farming might also increase the probability that a product will be chosen by a consumer). The increased "quality" of labeling increases the likelihood that the purchased milk product will be $m_{1}$; that is:

$$
\begin{aligned}
& P\left(m_{1}>0 \mid L 1\right)<P\left(m_{1}>0 \mid L 2\right) \\
& \quad<P\left(m_{1}>0 \mid L 3\right) .
\end{aligned}
$$

If income effects are relatively small, Marshallian demand functions will not differ significantly from Hicksian demand functions. Small income elasticities for fluid milk estimated in previous studies, e.g., Heien and Wessells, suggest that own-price effects for branded fluid milk products are likely to be negative for the Marshallian demand functions derived from this model. Inequality (6) represents the primary prediction that will be investigated empirically using retail scanner data.

Additional information that increases human capital regarding $\mathrm{rBGH}$ will influence the likelihood of purchase in a manner analogous to the effect of labeling changes in equation (5). For example, new reliable scientific information that portrays $\mathrm{rBGH}$ negatively (positively) in regard to health and environmental risks would increase (decrease) the stochastic difference in utilities $\left(V^{*}\right)$ through a decrease in uncertainty. While this predicted probability increase (decrease) could occur with or without additional labeling information, a change in $H$ is also likely to alter the labeling effect. 
Labeling becomes more (less) valuable to consumers as their expected difference in utilities changes. Additionally, advocacy by scientists in favor of biotechnology such as that called for in Beachy could lead to reduction in the labeling effect over time.

\section{Data}

National-level supermarket scanner data for fluid milk demand were combined with information about the use of $\mathrm{rBGH}$ in milk production and product-specific labeling to evaluate labeling effects. Over 13,000 supermarkets, either belonging to national chains or operating independently, which were located in sixty-four U.S. metropolitan areas, were tracked by IRI. ${ }^{3}$ Quantities sold and prices were initially tracked over thirteen-week periods from January 1995 to December 1997 and then over four-week periods from January 1998 to December 1999. The sales quantities collected by IRI were aggregated across the 64 metropolitan areas at the product code (UPC) level. Prices were temporally aggregated (first within the initial thirteen-week tracking period and then over the four-week period) and spatially aggregated and were based on list prices that did not take advertised sales into account.

The analysis focuses on branded beverage milk, excluding buttermilk and flavored milk, and only considers half-gallon and gallon containers. Branded products included in the IRI data set do not necessarily compete directly with one another in all markets. Therefore, supermarket-owned brand labels, e.g., Safeway and Albertsons store brands, are aggregated to form a "reference" product or brand that represents "conventional" milk products that are typically produced with $\mathrm{rBGH}$. The sales and prices of all other milk brands in our sample are compared to the sales and prices of this reference brand. ${ }^{4}$ Aggregate nationwide supermarket sales include sales of milk under the supermarkets' own labels as well as branded milk in all container sizes, including quarts, pints, etc. The data set does not allow the computation of market share with respect

\footnotetext{
${ }^{3}$ IRI uses the food industry's definition of a supermarket: A grocery store with dairy, produce, fresh meat, package food, and non-food departments and annual sales of $\$ 2$ million or more. Sales from either health food stores, food cooperatives, or natural food stores are not included.

${ }^{4}$ Mathios uses a similar specification where he defines his dependent variable as the log of the ratio of units sold of a product to units sold of a reference brand, in his case in supermarket $s$ at time $t$.
}

to branded milk alone. According to Glaser and Thompson, branded milk accounted for about $1 / 3$ of supermarket milk volume sales over the time period investigated in this study.

Prices and unit sales for different branded fluid milk products offered by different milk processors were obtained from the IRI database and combined with information about the use of $\mathrm{rBGH}$ in milk production and the milk processor's labeling practice during the period of 1995-99. Approximately $10 \%$ of fluid milk in the United States was labeled rBGH-free during this period. Products included in the analysis were selected as follows. First, firms that process rBGH-free milk were identified using a comprehensive list complied by Rural Vermont and Mothers and Others (Purefood) and additional information regarding retail milk markets to contact processors. The authors then conducted a survey of those milk processors. Thirteen processors provided sufficiently reliable information about the use of rBGH and labeling characteristics to be included in the analysis. These thirteen firms, which jointly produced a total of 202 different branded products, are estimated to have had $3.9 \%$ market share for skim and low-fat milk sales and $2.4 \%$ market share for whole fat milk sales in supermarkets nationwide over the sample period. These thirteen firms include four firms with brands available nationwide, eight multistate regional processors that in aggregate covered almost all regions of the country, and one firm that served only California. Two of the thirteen processors sold $\mathrm{rBGH}$-free milk brands that were not labeled as $\mathrm{rBGH}-$ free, seven sold fluid milk products that were labeled as rBGH-free, three sold organic milk products, and five sold conventional milk products. Four milk processors produced items in more than one of the three general product categories; for example, one firm in this sample produced both organic and labeled rBGH-free branded products.

None of the thirteen processors changed their policy with regard to $\mathrm{rBGH}$ use or labeling over the period 1995-99. Four categories of branded milk products-conventional, unlabeled rBGH-free, labeled rBGH-free, and organic-were available in supermarkets over the entire time period. However, organic milk products sold in gallon containers were not included in the data set until April 1998. The categorical product level data on rBGH-characteristics obtained in the survey of milk processors were coded using three mutually exclusive zero-one dummy variables 
(rBGHfreenonlabeled, rBGHfreelabeled, and organic) where the conventional milk product is the base case.

Comparisons of means tests were carried out to assess whether prices differed among product categories. The results indicated that price differences among these branded product categories were statistically significant at less than the $1 \%$ level for every fat content and container size category between $(a)$ non-organic labeled $\mathrm{rBGH}$-free products and conventional products, $(b)$ organic products and conventional products, and $(c)$ between products labeled $\mathrm{rBGH}$-free and unlabeled rBGH-free products. Milk products labeled rBGH-free were sold at premiums over conventional milk products that ranged from fourty-one to fourty-seven cents for halfgallons and thirty-four to fourty-nine cents for gallons. Similarly, organic milk products were also generally sold at premiums over conventional milk products that ranged from 98 cents to $\$ 1.16$ for half-gallons and $\$ 1.81$ to $\$ 2.49$ for gallons. Converting these premiums to percentages of the conventional prices yields a range from $26 \%$ to $30 \%$ for $\mathrm{rBGH}-$ free labeled milk in half-gallons and $13 \%$ to $17 \%$ for $\mathrm{rBGH}$-free labeled milk in gallons. Organic milk prices, however, were $63-75 \%$ higher than conventional milk prices for halfgallons and $65-90 \%$ higher than conventional milk prices for gallons. Nonlabeled rBGH-free milk products did not generally sell at a premium over conventional branded milk products in this data set.

In the econometric models presented below, the numerator for any given observation of the dependent variable is the quantity of the brand of interest that may be sold within either a state, a multistate region, or nationwide while the denominator is the quantity of the aggregate reference product sold nationwide. A market size variable (marketsize) was therefore constructed to serve as an instrument for geographically defined market size related effects among observations. Annual population estimates for the period 1995-99 reported by the U.S. Census Bureau for states in which the product was available were used to capture the number of potential consumers (in millions) for a given milk product. The data were organized into eight different fat content and container size categories to permit comparisons of clearly homogeneous products. For instance, demand functions for whole milk products in gallon containers are estimated separately from demand functions for $2 \%$ milk in gallon containers and for categories of milk in halfgallon containers. As noted above, a reference brand was defined within each fat content and container size category. This reference brand was used to construct two additional variables, the logarithm of quantity ratios between each milk product and its reference brand and the price difference between each milk product and its reference brand. The price and quantity data for the reference brands used in this computation consist of nationwide unit sales averages and price averages of supermarketowned labels that include milk produced with rBGH but do not have labels that indicate this fact to consumers. The aggregate nature of the reference brand data precludes it from serving as an instrument for differences in the size of market served by a specific brand; the market size variable discussed previously was used to instrument for these market sales differences.

The data set used in the econometric analysis consists of 5,840 observations. Each observation corresponds to a specific fluid milk product identified by its UPC. Between 1995 and 1997 these observations were collected for thirteen-week periods. However, in 1998 the data collection procedure changed, with observations from 1998 to 1999 collected for four-week tracking periods, and not all products were recorded in all time periods. Table 1 provides descriptive statistics for the variables included in the data set, where each observation records the relative unit sales, price, and other information for a single brand during a single tracking period. Table 2 provides market share data for fat content and container size categories of fluid milk products.

\section{Econometric Specification}

The representative individual's random utility model provides important predictions about the effects of rBGH-free labeling. Two implications for estimations follow from the IRI data used in this study. First, the IRI data set records aggregate (nationwide, across all consumers) purchase quantities of branded milk products over a number of weeks. Second, milk purchases at the individual level for the multiweek periods used here are also not "lumpy" in the McFadden sense because consumers are likely to have multiple purchases within each period. The dependent variable in the estimation models, therefore, is effectively continuous, and so a discrete choice econometric framework is not required. 
Table 1. Descriptive Statistics

\begin{tabular}{|c|c|c|c|c|c|}
\hline Variable & Observations & Mean & SD & Minimum & Maximum \\
\hline unitsales $_{m_{i}}$ & 5,840 & 137,490 & 220,847 & 1 & $2,030,569$ \\
\hline unitsales $_{m_{r}}$ & 312 & $8,351,017$ & $1.18 \times 10^{7}$ & 988,116 & $6.56 \times 10^{7}$ \\
\hline $\ln \left(\right.$ unitsales $_{m_{i}} /$ unitsales $\left._{m_{r}}\right)$ & 5,840 & -4.90 & 2.36 & -14.91 & -1.29 \\
\hline$P_{m_{j}}$ & 5,840 & 2.22 & 0.75 & 0.95 & 5.51 \\
\hline$P_{m_{r}}$ & 312 & 2.03 & 0.47 & 1.36 & 2.87 \\
\hline$P_{m_{i}}-P_{m_{r}}$ & 5,840 & 0.31 & 0.53 & -0.89 & 3.01 \\
\hline Marketsize & 5,840 & 130.33 & 103.61 & 12.58 & 272.70 \\
\hline rBGHfreenonlabeled & 5,840 & 0.08 & 0.28 & 0 & 1 \\
\hline rBGHfreelabeled & 5,840 & 0.28 & 0.45 & 0 & 1 \\
\hline Organic & 5,840 & 0.13 & 0.34 & 0 & 1 \\
\hline
\end{tabular}

Note: Terms $m_{i}$ and $m_{r}$ indicate quantities sold of the $i$ th branded product and of the supermarket reference brand, respectively. $P_{m_{i}}$ and $P_{m_{r}}$ are prices for these goods.

Table 2. Market Share of Fluid Milk Products across Fat Content and Container Size

\begin{tabular}{lccc}
\hline & Observations & Mean Unit Sales & \% of Total Unit Sales \\
\hline Half-gallon & 3,666 & 119,006 & 54.34 \\
Fat-free & 1,019 & 134,538 & 17.07 \\
$1 \%$ & 926 & 90,250 & 10.44 \\
$2 \%$ & 902 & 144,884 & 16.28 \\
Whole & 816 & 103,743 & 10.24 \\
Gallon & 2,174 & 168,660 & 45.67 \\
Fat-free & 665 & 151,659 & 12.56 \\
$1 \%$ & 388 & 142,955 & 6.90 \\
$2 \%$ & 572 & 223,691 & 15.94 \\
Whole & 549 & 150,083 & 10.26 \\
\hline
\end{tabular}

Additional assumptions are placed on the indirect utility function in equation (3) and on the error distribution to operationalize the model developed above for the available data. The representative consumer's indirect utility difference function presented in its general form in equation (3) for purchase and consumption of fluid milk product $m_{i}$ over multiple milk products is assumed to be linear; that is. ${ }^{5}$

$$
\begin{array}{r}
V_{i}^{*}=\left(A_{i} \beta+\varepsilon_{i}\right)-\left(A_{j} \beta+\varepsilon_{j}\right) \\
\text { for all } j \neq i .
\end{array}
$$

In equation (7), the vectors $A_{i}$ and $A_{j}$ indicate the attributes of milk brand $m_{i}$ and all alternative milk brands $m_{j}$, and the vector $\beta$ represents the weights the household places on each of these attributes. The error term in

\footnotetext{
${ }^{5}$ The focus of this analysis is the choice of fluid milk brands based on their attributes. This focus, plus the assumption that the choice of $x$ will be unchanged for different indirect utility functions, allows suppression of a constant term that relates to other goods consumed in this specification.
}

equation (7) is assumed to arise from randomness in attribute perception. As indicated in equation (4) for the two product case, purchase and consumption of fluid milk product $m_{i}$ over alternative milk products indicates that

$$
\begin{aligned}
& E\left[\left(A_{i} \beta+\varepsilon_{i}\right)-\left(A_{j} \beta+\varepsilon_{j}\right)\right]>0 \\
& \text { for all } j \neq i .
\end{aligned}
$$

Under an iid logistic distributional assumption, the probability that the $i$ th fluid milk product $\left(m_{i}\right)$ is purchased can then be written as:

$$
P\left(m_{i}>0\right)=\frac{\exp \left(A_{i} \beta\right)}{\sum_{j=1}^{n} \exp \left(A_{j} \beta\right)}
$$

where $\exp (\cdot)$ denotes the exponential function and $j=1,2, \ldots, n$ denotes all available milk products.

For uniformity of brand comparisons, the regressions make use of private-label supermarket milk sales as a reference brand for all milk sales. The relative odds of the representative 
consumer choosing product $m_{i}$ over the reference brand, $m_{r}$, are

$$
\frac{P\left(m_{i}>0\right)}{P\left(m_{r}>0\right)}=\frac{\exp \left(A_{i} \beta\right)}{\exp \left(A_{r} \beta\right)}
$$

The aggregate quantity ratios are consistent estimates of the likelihood ratios in equation (10). Redefining the left-hand side variable as unit sales of product $i$ divided by unit sales of a reference brand, and taking its logarithm, equation (10) can be written as a linear function of the parameters for estimation; that is,

$$
\ln \left(\frac{\text { unitsales }_{m_{i}}}{\text { unitsales }_{m_{r}}}\right)=\left(A_{i}-A_{r}\right) \beta .
$$

Equation (11) forms the basis for the estimation equations used in the empirical analysis. In this formulation, the vector $\left(A_{i}-A_{r}\right)$ denotes differences in attributes between the $i$ th fluid milk product and the reference brand. Here, the key component of this attribute difference vector is the information about whether a brand is produced with or without the use of $\mathrm{rBGH}$, or if the brand is certified as organic. This process characteristic is interacted with the information about product labeling. Not all of the processors that sell milk produced without the use of rBGH label their products as rBGH-free, while all of the organically produced milk products are labeled organic. The information on prices in the data set is expressed as the difference between the price of milk product $m_{i}$ and the price of the reference brand.

Demand differences resulting from attributes such as fat content and container size are allowed for in the estimations through separate regression equations for each one of the four fat contents (skim, $1 \%, 2 \%$, and whole) and the two container sizes (half-gallons and gallons). Each of these regression equations includes an error term due to error in the data collection process arising from aggregation or from abstraction from specific time of purchase information such as sales or promotions.

An important prediction of the theoretical model (equation (6)) is that milk products labeled as rBGH-free are more likely to be chosen by consumers who, ceteris paribus, have a positive difference in utility between rBGHfree and conventional milk. The magnitude of the coefficient for unlabeled rBGH-free products is predicted to be smaller than the magnitude of the coefficient for labeled rBGH-free products due to search costs. Intuitively, the coefficient for unlabeled rBGH-free milk may not be significantly different from zero.

The coefficient for the organic milk products dummy variable is predicted to be positive and of greater magnitude than the coefficient for $\mathrm{rBGH}$-free and labeled products. Organic milk production is certified by independent third parties and must meet standards set by individual states or new national standards. Organic milk therefore represents an increase in the quality of labeling over voluntary rBGH-free labeling by a processor. Additional factors such as concerns over pesticide residues or support of organic farming might also increase some household preferences for organic products. In addition, uncertainty about utility differences and the prediction with regard to availability of new reliable scientific information would result in either a decrease or increase of the coefficient for rBGH-free labeled milk products.

Econometric models of fluid milk demand were estimated separately for each fat content (fat-free, $1 \%, 2 \%$, and whole) and container size (half-gallons and gallons) to allow for varying levels of substitutability between these products. Sample sizes for each fat content and container-specific estimation consisted of more than 300 observations.

\section{Diagnostics}

There may have been some important structural changes in the fluid milk data over the estimation period (1995-99). Data on organic fluid milk in gallons were included in the data set beginning only in April 1998, with subsequent steady increases in aggregate sales. Additionally, the data-reporting period changed from a thirteen-week to a four-week period in 1998. Chow tests (Chow) were conducted to investigate evidence of structural change in the market in 1998. Absence of structural change was rejected as the null hypothesis at conventional levels for approximately $50 \%$ of the fat content/container size categories. The regression results reported below therefore include models estimated for the two sample sub-time periods 1995-97 and 1998-99 to permit comparisons across all products with respect to evidence of structural change. Parameter estimates for the split samples do not in fact differ greatly from estimates based on the entire sample.

Several tests for heteroskedasticity were performed on the data set. The general (Breusch and Pagan) test indicated the 
presence of heteroskedasticity for all fat content levels and container sizes. Restricted tests that related the error structure to specific explanatory variables failed to reject the null hypothesis (White). Heteroskedasticity in the data appears to be introduced by a number of factors that cannot be easily separated. Consequently, all regression models were estimated in a generalized least squares (GLS) form and White-corrected standard errors are reported. Finally, no significant autocorrelation problems were detected in the sample.

The firms included in the analysis comprise less than $5 \%$ of nationwide supermarket fluid milk sales in the IRI database. Thus, the fluid milk supply curve from dairy farmers to these relatively small segments of the fluid milk market for branded products (conventional, rBGH-free, and organic) is expected to be relatively price elastic. The derived retail fluid milk supply curves may not be so price elastic. Price/quantity relationships for retail supply that relate to the costs of monitoring and enforcing rBGH-free labels are of particular interest. These costs are generally incurred at the milk processing firm level, and may differ across firms. Although we do not have useful measures for firm-specific costs for fluid milk supply at the retail level, we instrument for them in the estimated demand models through firm-specific dummy variables for the thirteen milk processors included in the sample.
Several alternatives to the instrumental variables approach are available that differ in the treatment of firm-specific effects, including fixed-effect models. Fixed-effects models of demand were estimated without instrumenting for firm cost effects. These models yielded very similar qualitative results to the instrumental variables approach. There were also generally no significant improvements in model fit when a random effects approach was utilized. $\mathrm{Pa}-$ rameter estimates based on the instrumental variables approach are reported because of their potential to account for firm-specific cost differences in monitoring and enforcement for rBGH-free labels as well as advertisement.

\section{Regression Results}

Results for the instrumental variables regression models are presented in tables 3-6 for the two sample time periods (1995-97 and 199899) and for each fat content and container size combination. In each regression, as implied by equation (11), the ratio of market sales for the $i$ th brand to market sales of the supermarket reference commodity is a function of attribute differences between those commodities, including differences in prices. Estimated coefficients for price difference variables are negative and statistically significant for almost all fat content and container size combinations

Table 3. Regression Results for Half-Gallon, Fat-Free and 1\% Milk. Dependent Variable: Logarithm of Relative Quantities

\begin{tabular}{|c|c|c|c|c|}
\hline \multirow[b]{2}{*}{ Independent Variable } & \multicolumn{2}{|c|}{ Fat-Free } & \multicolumn{2}{|c|}{$1 \%$} \\
\hline & 1995-97 & 1998-99 & 1995-97 & 1998-99 \\
\hline Constant & $\begin{array}{c}-4.02^{* * *} \\
(0.23)\end{array}$ & $\begin{array}{c}-4.27^{* * *} \\
(0.09)\end{array}$ & $\begin{array}{c}-3.75^{* * *} \\
(0.14)\end{array}$ & $\begin{array}{c}-4.27^{* * *} \\
(0.08)\end{array}$ \\
\hline Marketsize & $\begin{array}{l}0.001 \\
0.001\end{array}$ & $\begin{array}{c}0.0005 \\
(0.0006)\end{array}$ & $\begin{array}{c}0.004^{* * *} \\
(0.0008)\end{array}$ & $\begin{array}{c}0.002^{* * *} \\
(0.0006)\end{array}$ \\
\hline$P_{m_{i}}-P_{m_{r}}$ & $\begin{array}{c}-0.89 \\
(0.96)\end{array}$ & $\begin{array}{c}-3.13^{* * *} \\
(0.33)\end{array}$ & $\begin{array}{c}-3.33^{* * *} \\
(0.73)\end{array}$ & $\begin{array}{c}-2.89^{* * *} \\
(0.21)\end{array}$ \\
\hline rBGHfreenonlabeled & $\begin{array}{c}-0.59 \\
(0.39)\end{array}$ & $\begin{array}{c}-1.67^{* * *} \\
(0.34)\end{array}$ & $\begin{array}{c}-2.44^{* * *} \\
(0.32)\end{array}$ & $\begin{array}{c}-1.60^{* * *} \\
(0.24)\end{array}$ \\
\hline rBGHfreelabeled & $\begin{array}{c}-0.29 \\
(0.34)\end{array}$ & $\begin{array}{l}0.56^{* * *} \\
(0.20)\end{array}$ & $\begin{array}{c}0.10 \\
(0.23)\end{array}$ & $\begin{array}{l}0.87^{* * *} \\
(0.17)\end{array}$ \\
\hline Organic & $\begin{array}{c}0.33 \\
(0.97)\end{array}$ & $\begin{array}{l}3.81^{* * *} \\
(0.42)\end{array}$ & $\begin{array}{c}-0.15 \\
(1.01)\end{array}$ & $\begin{array}{l}1.83^{* * *} \\
(0.43)\end{array}$ \\
\hline Sample size & 309 & 710 & 257 & 672 \\
\hline Degrees of freedom & 303 & 704 & 251 & 666 \\
\hline$F$-statistic & 1.34 & 28.32 & 41.94 & 72.25 \\
\hline
\end{tabular}

Note: Standard errors are corrected for heteroskedasticity and reported in parentheses. ${ }^{*},{ }^{* *}$, and ${ }^{* * *}$ denote coefficients that are statistically different from 0 at the $10 \%, 5 \%$, and $1 \%$ level. Terms $m_{i}$ and $m_{r}$ indicate quantities sold of the $i$ th branded product and of the supermarket reference brand, respectively. $P_{m_{i}}$ and $P_{m_{r}}$ are prices for these goods. 
Table 4. Regression Results for Half-Gallon, $2 \%$ and Whole Milk. Dependent Variable: Logarithm of Relative Quantities

\begin{tabular}{lccccc}
\hline & \multicolumn{2}{c}{$2 \%$} & & \multicolumn{2}{c}{ Whole } \\
\cline { 2 - 3 } \cline { 5 - 6 } Independent Variable & $1995-97$ & $1998-99$ & & $1995-97$ & $1998-99$ \\
\hline Constant & $-3.67^{* * *}$ & $-4.62^{* * *}$ & & $-4.49^{* * *}$ & $-4.39^{* * *}$ \\
& $(0.18)$ & $(0.16)$ & & $(0.23)$ & $(0.11)$ \\
Marketsize & 0.001 & $0.003^{* * *}$ & $0.003^{* * *}$ & $0.001^{*}$ \\
& $(0.001)$ & $(0.0007)$ & & $(0.001)$ & $(0.0008)$ \\
$P_{m_{i}}-P_{m_{r}}$ & $-3.88^{* * *}$ & $-3.39^{*}$ & & $-4.50^{* * *}$ & $-3.96^{* * *}$ \\
$r B G H f r e e n o n l a b e l e d$ & $(0.59)$ & $(0.28)$ & & $(0.71)$ & $(0.30)^{*}$ \\
& $-2.90^{* * *}$ & $-2.02^{* * *}$ & & $-1.89^{* * *}$ & $-2.71^{* * *}$ \\
$r B G H f r e e l a b e l e d$ & $(0.46)$ & $(0.38)$ & & $(0.51)$ & $(0.44)$ \\
& -0.16 & $0.66^{* * *}$ & & 0.08 & 0.17 \\
Organic & $(0.21)$ & $(0.18)$ & $(0.30)$ & $(0.17)$ \\
& $2.15^{* * *}$ & $3.85^{* * *}$ & & $2.61^{* * *}$ & $4.10^{* * *}$ \\
Sample size & $(0.69)$ & $(0.38)$ & & $(0.83)$ & $(0.39)$ \\
Degrees of freedom & 301 & 601 & 251 & 565 \\
F-statistic & 295 & 595 & 245 & 559 \\
\hline
\end{tabular}

Note: Standard errors are corrected for heteroskedasticity and reported in parentheses. ${ }^{*},{ }^{* *}$, and ${ }^{* * *}$ denote coefficients that are statistically different from 0 at the $10 \%, 5 \%$, and $1 \%$ level. Terms $m_{i}$ and $m_{r}$ indicate quantities sold of the $i$ th branded product and of the supermarket reference brand, respectively. $P_{m_{i}}$ and $P_{m_{r}}$ are prices for these goods.

Table 5. Regression Results for Gallon, Fat-Free and 1\% Milk. Dependent Variable: Logarithm of Relative Quantities

\begin{tabular}{lccccc}
\hline & \multicolumn{2}{c}{ Fat-Free } & & \multicolumn{2}{c}{$1 \%$} \\
\cline { 2 - 3 } \cline { 5 - 6 } Independent Variable & $1995-97$ & $1998-99$ & & $1995-97$ & $1998-99$ \\
\hline Constant & $-6.59^{* * *}$ & $-7.04^{* * *}$ & & $-4.05^{* * *}$ & $-3.61^{* * *}$ \\
& $(0.32)$ & $(0.17)$ & & $(0.47)$ & $(0.12)$ \\
Marketsize & $0.005^{* * *}$ & $0.005^{* * *}$ & & $0.004^{* * *}$ & 0.001 \\
& $(0.002)$ & $(0.0009)$ & & $(0.002)$ & $(0.0009)$ \\
$P_{m_{i}}-P_{m_{r}}$ & $-3.54^{* *}$ & $-2.97^{* * *}$ & & $-2.87^{* * *}$ & $-3.05^{* * *}$ \\
$r B G H f r e e n o n l a b e l e d$ & $(0.68)$ & $(0.27)$ & & $(1.05)$ & $(0.41)$ \\
& $2.01^{* * *}$ & $2.09^{* * *}$ & & -0.61 & $-1.41^{* * *}$ \\
$r B G H f r e e l a b e l e d$ & $(0.31)$ & $(0.17)$ & & $(0.85)$ & $(0.30)$ \\
& $1.41^{* * *}$ & $1.21^{* * *}$ & & 0.31 & 0.26 \\
Organic & $(0.47)$ & $(0.28)$ & & $(0.42)$ & $(0.23)$ \\
& - & $3.05^{* * *}$ & & - & $2.37^{*}$ \\
Sample size & 184 & $(0.69)$ & & 121 & 267 \\
Degrees of freedom & 179 & 481 & 116 & 261 \\
$F$-statistic & 74.93 & 144.39 & 9.21 & 26.55 \\
\hline
\end{tabular}

Note: Standard errors are corrected for heteroskedasticity and reported in parentheses. ${ }^{*},{ }^{* *}$, and ${ }^{* * *}$ denote coefficients that are statistically different from 0 at the $10 \%, 5 \%$, and $1 \%$ level. Terms $m_{i}$ and $m_{r}$ indicate quantities sold of the $i$ th branded product and of the supermarket reference brand, respectively. $P_{m_{i}}$ and $P_{m r}$ are prices for these goods.

and in both time periods. These coefficient estimates range from -2.89 to -4.50 for halfgallons and from -1.00 to -3.54 for gallons, indicating that the logarithm of the ratio of the quantity of its sales to the quantity of sales of the reference brand is inversely related to the price difference between that product and the reference brand.
Estimates for the marketsize variable coefficients are positive and significant in most regressions, suggesting that, ceteris paribus, as the potential market for a product increases, sales increase relative to the reference brand. This result is consistent with the hypothesis that there are economies of scale associated with serving larger markets. 
Table 6. Regression Results for Gallon, $2 \%$ and Whole Milk. Dependent Variable: Logarithm of Relative Quantities

\begin{tabular}{lccccc}
\hline & \multicolumn{2}{c}{$2 \%$} & & \multicolumn{2}{c}{ Whole } \\
\cline { 2 - 3 } \cline { 5 - 6 } Independent Variable & $1995-97$ & $1998-99$ & & $1995-97$ & $1998-99$ \\
\hline Constant & $-5.35^{* * *}$ & $-5.22^{* * *}$ & & $-4.78^{* * *}$ & $-4.47^{* * * *}$ \\
& $(0.41)$ & $(0.21)$ & & $(0.31)$ & $(0.21)$ \\
Marketsize & $0.005^{* * *}$ & $0.005^{* * *}$ & & $0.003^{* * *}$ & $0.003^{* *}$ \\
& $(0.001)$ & $(0.001)$ & & $(0.001)$ & $(0.0007)$ \\
$P_{m i}-P_{m r}$ & $-1.00^{*}$ & $-2.49^{* * *}$ & & $-1.69^{* * *}$ & $-2.52^{* * *}$ \\
$r B G H f r e e n o n l a b e l e d$ & $(0.52)$ & $(0.27)$ & & $(0.54)$ & $(0.29)$ \\
& 0.78 & 0.48 & & -0.09 & $-1.04^{* * *}$ \\
$r B G H f r e e l a b e l e d$ & $(0.71)$ & $(0.41)$ & & $(0.49)$ & $(0.33)$ \\
& -0.13 & $0.90^{* * *}$ & & $0.96^{* * *}$ & $1.57^{* * *}$ \\
Organic & $(0.34)$ & $(0.25)$ & & $(0.33)$ & $(0.22)$ \\
& - & $(0.56)$ & & - & $3.81^{* * *}$ \\
Sample size & 183 & 389 & 164 & $(0.66)$ \\
Degrees of freedom & 178 & 383 & 159 & 376 \\
$F$-statistic & 6.50 & 48.23 & 4.01 & 25.46 \\
\hline
\end{tabular}

Note: Standard errors are corrected for heteroskedasticity and reported in parentheses. ${ }^{*},{ }^{* *}$, and ${ }^{* * *}$ denote coefficients that are statistically different from 0 at the $10 \%, 5 \%$, and $1 \%$ level. Terms $m_{i}$ and $m_{r}$ indicate quantities sold of the $i$ th branded product and of the supermarket reference brand, respectively. $P_{m i}$ and $P_{m_{r}}$ are prices for these goods.

The parameter estimates for $r B G H$ freelabeled are of central interest in this study. For the first time period (1995-97), these coefficients are both positive and statistically significant for only two products, fat-free and whole milk in gallons. For the second period (199899), when the data were collected over more frequent intervals, parameter estimates are significant and positive in three-quarters of the regressions (six out of eight cases). Coefficient estimates for $\mathrm{rBGH}$-free labeled milk range from 0.56 to 0.87 for half-gallons and from 0.90 to 1.57 for gallons. These results are consistent with the predictions of the theoretical model. They indicate that, ceteris paribus, by reducing information search costs labeling improves the quality of information about product characteristics and increases consumption of milk labeled rBGH-free. The estimated coefficients for the labeling variables are potentially affected by an omitted variables bias in the data set because information about advertising expenditures on specific products, promotional sales, and shelf placement could not be included simply because it could not be observed. However, it should be noted that firmspecific dummy variables were included in the estimation to at least partially account for the effects of these omitted variables.

The differences in the coefficient estimates for the two time periods suggest that over time consumers may alter the degree to which they adjust their purchase decisions in response to different labels, for rBGH-free milk. It should be noted that the difference in estimated coefficients might be associated with the change in the frequency with which the data were collected in 1998. In contrast to some claims, however, there is no evidence that consumer preferences for $\mathrm{rBGH}$-free milk have declined over the period in response to publicly provided scientific information that $\mathrm{rBGH}$ milk has few, if any, harmful health effects.

Table 7 presents quantity ratios, quantities, and differences computed at the sample means to assess the $r B G H$ freelabeled effect. While the changes in the ratios are relatively small, quantities almost double for product categories where this coefficient is statistically significant.

No consistent results were obtained with respect to the dummy variable for $\mathrm{rBGH}$-free products that were not labeled as such. The estimated coefficients for rBGHfreenonlabeled in tables 3-6 are either negative and significant, or positive and significant, or insignificant across fat content and container size categories and time periods and exhibit no discernable pattern. These results indicate that the provision of relevant information on a product label may be required if market segmentation is to take place between conventional and rBGHfree products. However, the small number of firms (2) that sell rBGH-free but unlabeled milk products may mean that these coefficients are also capturing the effects of unobservable variables such as advertising expenditures, 


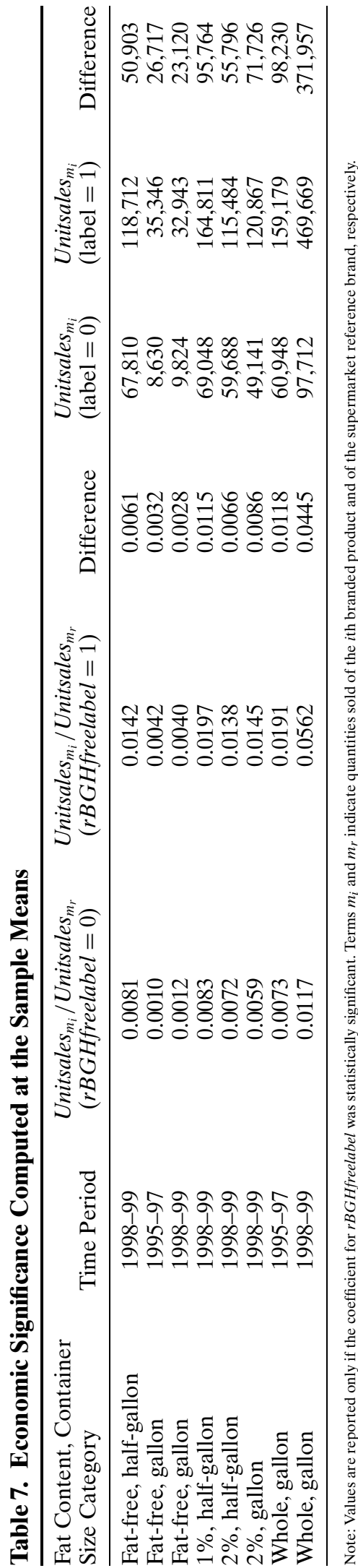

promotional sales, and shelf life not accounted for by the firm-specific dummy variables.

Parameter estimates for the organic fluid milk dummy variable are generally positive and significant, ranging from 1.83 to 4.10 for half-gallons and 1.28 to 3.81 for gallons. $\mathrm{Pa}-$ rameter estimates for gallons could only be obtained for the second time period (1998-99) because organic milk sold in gallon containers did not appear in the data set until April 1998. These parameter estimates are greater in magnitude than the estimates for the rBGH-free labeled variable, a finding consistent with the prediction of the theoretical model presented above. While additional factors such as concerns over pesticide residues or support of organic farming might increase preferences for organic products, the magnitude of these coefficients may also be influenced by market penetration of organic milk products. An increasing number of supermarkets added organic products to their product palette over the estimation period resulting in steadily increasing sales in the data set. ${ }^{6}$

The parameter estimates reported in tables 3-6 indicate that labeling alters the milk consumption decisions of some consumers. Thus, while it is not feasible to obtain quantitative estimates for the welfare effects of labeling with the information available, these results suggest that increased labeling enhances consumer welfare.

The empirical model specifications also permit the computation of aggregate unit sales differences and own-price demand elasticity estimates for $\mathrm{rBGH}$-free labeled and conventional fluid milk. ${ }^{7}$ Table 7 presents the estimated unit

\footnotetext{
${ }^{6}$ A model specification that added an interaction term between organic and year was used to control for market penetration did not yield significantly different estimates and $F$-tests did not indicate improved explanatory power in most regressions.

${ }^{7}$ The following regression was estimated using an instrumental variables approach:

$$
\begin{aligned}
\ln \left(\frac{\text { unitsales }_{m_{i}}}{\text { unitsales }_{m_{r}}}\right)= & \alpha_{0}+\alpha_{1} \text { marketsize } \\
& +\beta_{1} \text { rBGHfreelabeled } \\
& +\beta_{2}\left(P_{m_{i}}-P_{m_{r}}\right) \text { rBGHfreelabeled } \\
& +\beta_{3}\left(P_{m_{i}}-P_{m_{r}}\right) \text { conventional. }
\end{aligned}
$$
}

The price difference and $\mathrm{rBGH}$-characteristic interaction terms were instrumented using the same exogenous variables as in the primary model. Carrying out appropriate transformations, price elasticities for rBGH-free labeled milk can be derived as follows:

$$
\eta=\text { unitsales }_{m_{r}} \times \mathrm{e}^{\beta_{2} P_{m_{i}}} \times \beta_{2} \frac{P_{m_{i}}}{\text { unitsales }_{m_{i}}} .
$$

For conventional milk, the same equation is used, substituting $\beta_{3}$ for $\beta_{2}$. 
Table 8. Price Elasticities Computed at the Sample Means

\begin{tabular}{lll}
\hline & \multicolumn{2}{c}{ 1998-99 } \\
\cline { 2 - 3 } & rBGH-Free Labeled & Conventional \\
\hline Half-gallon & & \\
Fat-free & -0.28 & -0.14 \\
$1 \%$ & -0.002 & -0.68 \\
$2 \%$ & -0.14 & - \\
Whole & -0.05 & -2.35 \\
Gallon & & -0.00002 \\
Fat-free & -0.95 & -0.0002 \\
$1 \%$ & -0.36 & -0.0004 \\
$2 \%$ & -0.56 & -1.57 \\
Whole & -0.12 & \\
\hline
\end{tabular}

Note: Estimated price elasticities reported in the table are significant at the $1 \%$ significance level, except for the half-gallon, $2 \%$ conventional that is significant at the $5 \%$ significance level.

sales differences between milk product categories using sample means. Estimated relative and absolute unit sales differences are consistently higher for labeled than for unlabeled biotechnology-free milk. Table 8 presents the own-price elasticity estimates for $\mathrm{rBGH}$-free labeled and conventional milk for the second time period. ${ }^{8}$ Both of these categories include only branded milk products and the own-price elasticity estimates reported here are specific to fat levels and container sizes. These elasticity estimates range from -0.002 to -0.28 for $\mathrm{rBGH}$-free labeled milk in half-gallons and -0.12 to -0.95 in gallons, and from -0.14 to -2.35 for conventional milk in half-gallons and -0.00002 to -1.57 in gallons. Note that these elasticity estimates are subject to the caveat that the data set does not allow inclusion of demographic data or expenditure data, nor do the elasticity estimates include prices of potential substitution goods, e.g., soymilk or milk products outside the sample.

While some of the elasticity estimates are smaller in absolute magnitude than previously reported price elasticities, in the aggregate, the results do not differ markedly from previous studies, e.g., Glaser and Thompson; Green and Park; Gould; Heien and Wessells; Teisl,

\footnotetext{
${ }^{8}$ Price elasticity measures were only computed if $\beta_{2}$ and/or $\beta_{3}$ were statistically significant in the regression specification. For the first time period a number of the coefficients were insignificant, making comparisons between the elasticities impossible. In addition, the data entries for the two rBGH-free non-labeled brands do not provide sufficient price variation between brands to investigate price elasticities and market penetration of organic milk products over the estimation period, resulting in positive coefficients for an interaction term between price differences and the organic characteristic.
}

Bockstael, and Levy. The elasticity estimates as a whole suggest no clear pattern in response to price changes between rBGH-free labeled and conventional milk. If only the estimated price elasticities for gallon milk products are considered, consumers appear more responsive to price changes in $\mathrm{rBGH}$-free labeled milk than in conventional milk, but for half-gallon products, there is little evidence of similar effects. It is important to note that differently labeled fluid milk products appear to have different price elasticities of demand.

\section{Conclusion}

This study has developed a household production model of the effects of labeling that explicitly accounts for both search costs and uncertainty about product attributes and information within a random utility framework. A clear implication of this model is that the provision of additional positive information will, ceteris paribus, increase consumption of the commodity that has a desirable, but costly to observe, characteristic and reduce consumption of a competing commodity with an undesirable characteristic.

The predictions of the model were tested utilizing actual purchases in supermarkets of fluid milk brands produced either with rBGH or without rBGH. Branded milk excludes private-labeled supermarket brands. The brands in our sample comprised $3.9 \%$ of total low-fat and $2.4 \%$ of total whole fat nationwide supermarket milk sales during the sample period. The econometric results of the study indicate that, ceteris paribus, the provision of labeling information increases the quantity demanded of $\mathrm{rBGH}$-free branded milk, a result consistent with the predictions of the theoretical model. These results also confirm the findings of previous studies based on surveys of consumer attitudes which indicate that some consumers have preferences for milk and other foods that are produced without biotechnology.

Another interesting result is that this study provides no evidence that consumer preferences for $\mathrm{rBGH}$-free milk products have diminished over time. If anything, the positive effects of labeling on the demand for $\mathrm{rBGH}$ free fluid milk appear to have increased in the period 1998-99 as compared to the period 1995-97.

One limitation of this study derives from the aggregate nature of the scanner data used 
in the empirical analysis. Aggregation to the national level, an unavoidable requirement given the available data set, precludes any evaluation of regional and household demographic and socioeconomic variables that affect consumption choices. An important extension of this study would be to develop and analyze time-series/cross-section panel data sets that track individual households over sufficiently long time periods to investigate the evolution of consumer attitudes and market choices with respect to biotech products and biotech labeling. Another limitation is that the results might be influenced by omitted variables that are practically not possible to include such as product-specific advertising, shelf placements, and promotional sales. In addition, this study has considered only a subset of milk products sold in supermarkets, comprising less than $5 \%$ of nationwide fluid milk sales, because of limited information on labeling. Notwithstanding these limitations, this study provides the first estimates we know of about the impact of biotech labeling on actual retail purchases of a food product using regional and national data.

\section{[Received November 2002; accepted July 2004.]}

\section{References}

Aldrich, L., and N. Blisard. "Consumer Acceptance of Biotechnology. Lessons from the rbSt Experience." U.S. Department of Agriculture, Economic Research Service, Current Issues in Economics of Food Markets, Agr. Inf. Bull. No. 747-01, December, 1998.

Beachy, R.N. "Facing Fear in Biotechnology." Science July 1999: 335.

Becker, G.S. "A Theory of Allocation of Time." The Economic Journal 75(1965):493-517.

Breusch, T.S., and A.R. Pagan. "A Simple Test for Heteroskedasticity and Random Coefficient Variation." Econometrica 47(1979):1487-94.

Burton, M.P., J.S. Metcalfe, and V.H. Smith. "Innovation and the Demand for Food and Drug Labeling Regulation in an Evolutionary Model of Industry Dynamics." Structural Change and Economic Dynamics 12(2001):457-77.

Caswell, J.A., and D.I. Padberg. "Toward a More Comprehensive Theory of Food Labels." American Journal of Agricultural Economics 74(1992):460-68.

Chow, G.C. "Tests of Equality between Sets of Coefficients in Two Linear Regressions." Econometrica 28(1960):591-605.
"Gentechnik. Sinnloses Label." Der Spiegel 28(2003):160-62.

Glaser, L.W., and G.D. Thompson. "Demand for Organic and Conventional Beverage Milk." Paper presented at the Western Agricultural Economics Association Annual Meetings, Vancouver, British Columbia, 29 June-1 July 2000.

Golan, E., F. Kuchler, and L. Mitchell. Economics of Food Labeling. Economic Research Service, U.S. Department of Agriculture, Agricultural Economic Report No. 793, December 2000.

Gould, B.W. "Factors Affecting U.S. Demand for Reduced-Fat Fluid Milk." Journal of Agricultural and Resource Economics 21(1996):6881.

Green, G.M., and J.L. Park. "New Insights into Supermarket Promotions via Scanner Data Analysis: The Case of Milk." Journal of Food Distribution Research 29(1998):44-53.

Grobe, D., and R. Douthitt. "Consumer Acceptance of Recombinant Bovine Growth Hormone: Interplay between Beliefs and Perceived Risks." The Journal of Consumer Affairs 25(1995):12843.

Grossmann, S.J. "The Informational Role of Warranties and Private Disclosure about Product Quality." The Journal of Law and Economics 24(1981):461-83.

Heien, D.M., and C.R. Wessells. "The Demand for Dairy Products: Structure, Prediction, and Decomposition." American Journal of Agricultural Economics 70(1988):219-28.

Heiman, A., D.R. Just, and D. Zilberman. "The Role of Socio-economic Factors and Life Style Variables in Attitude and the Demand for Genetically Modified Foods." Journal of Agribusiness 18(1995):249-60.

Ippolito, P.M., and A.D. Mathios. "Information, Advertising and Health Choices: A Study of the Cereal Market." Rand Journal of Economics 21(1990):459-80.

McFadden, D. "The Measurement of Urban Travel Demand." Journal of Public Economics 3(1974):303-28.

McGuirk, A.M., W.P. Preston, and G.M. Jones. "Introducing Foods Produced Using Biotechnology: The Case of Bovine Somatotropin." Southern Journal of Agricultural Economics 24(1992):209-23.

Mathios A.D. "The Impact of Mandatory Disclosure Laws on Product Choices: An Analysis of the Salad Dressing Market." Journal of Law and Economics 43(2000):651-75.

Misra, S.K., and D.C. Kyle. "Demand for Milk Produced with and without Recombinant Bovine Somatotropin." Journal of Agribusiness 16(1998):129-40. 
Mojduszka, E.M., and Caswell, J.A. "A Test of Nutritional Quality Signaling in Food Markets Prior to Implementation of Mandatory Labeling." American Journal of Agricultural Economics 82(2000):298-309.

Monsanto. Status Update: Posilac Bovine Somatotropin. 2002. http://www.monsantodairy.com/ updates/Bovine.htm\#general (accessed March 2002).

Purefood (Organic Consumer Association). Who Offers rBGH-Free milk? 2003. http://www. purefood.org/starbucks/dairy.htm (accessed July 2003).

Rosen, S. "Hedonic Prices and Implicit Markets: Product Differentiation in Pure Competition." Journal of Political Economy 82(1974):34-55.

Smallwood, D.M., and J.R. Blaylock. "Consumer Demand for Food and Food Safety: Models and Applications." In J.A. Caswell, ed. Economics of Food Safety. New York: Elsevier Science Publishing Co., 1991, pp. 4-27.

Stigler, G.J. "The Economics of Information." Journal of Political Economy 69(1961):213-25.

Stigler, G.J., and G.S. Becker. "De Gustibus Non Est Disputandum." American Economic Review 67(1977):76-90.
Teisl, M.F., and B. Roe. "The Economics of Labeling: An Overview of Issues for Health and Environmental Disclosure." Agricultural and Resource Economics Review 28(1998):14050.

Teisl, M.F., B. Roe, and R.L. Hicks. "Can Ecolabels Tune a Market? Evidence from Dolphin Safe Labeling." Journal of Environmental Economics and Management 43(2002):339-59.

Teisl, M.F., N.E. Bockstael, and A. Levy. "Measuring the Welfare Effects of Nutrition Labeling." American Journal of Agricultural Economics 83(2001):133-49.

Thompson, G.D., and J. Kidwell. "Explaining the Choice of Organic Produce: Cosmetic Defects Prices and Consumer Preferences." American Journal of Agricultural Economics 80(1998):277-87.

U.S. Census Bureau. State Population Estimates; Annual Time Series, July 1, 1990 to July 1999. 1999. http://www.census.gov/population/estimates/ state/st.-99-3.txt (accessed September 2001).

White, H. "A Heteroskedasticity-Consistent Covariance Matrix Estimator and a Direct Test for Heteroskedasticity." Econometrica 48(1980):817-38. 
Copyright of American Journal of Agricultural Economics is the property of Blackwell Publishing Limited and its content may not be copied or emailed to multiple sites or posted to a listserv without the copyright holder's express written permission. However, users may print, download, or email articles for individual use. 